\title{
Erratum to: Concurrent Mental Health and Substance Use Problems Among Street-Involved Youth
}

\author{
Maritt Kirst • Tyler Frederick • Patricia G. Erickson
}

Published online: 20 July 2011

(C) Springer Science+Business Media, LLC 2011

\section{Erratum to: Int J Ment Health Addiction DOI 10.1007/s11469-011-9328-3}

The percentage in Table 1 for 'suicidal ideation in last 12 months' should be $27 \%$.

In Table 3, the number of homeless youth without a concurrent disorder reporting a previous arrest should be 51 .

The online version of the original article can be found at http://dx.doi.org/10.1007/s11469-011-9328-3.

M. Kirst $(\bowtie)$

Ontario Tobacco Research Unit, Dalla Lana School of Public Health, University of Toronto, Toronto, Canada

e-mail: maritt.kirst@utoronto.ca

T. Frederick $\cdot$ P. G. Erickson

Department of Sociology, University of Toronto, Toronto, Canada

P. G. Erickson

Social \& Epidemiological Research Department, Centre for Addiction and Mental Health, Toronto, Canada 